\title{
Tire Art: Environmental Education through Science, Visual and Language Arts
}

\author{
Young Imm Kang Song ${ }^{1}$, Maureen Creegan-Quinquis ${ }^{2}$, DongSun $\mathrm{Min}^{3}$, \& HuiKyeong Kang ${ }^{4}$ \\ ${ }^{1}$ Associate Professor, Creative Arts in Learning Div. Graduate School of Education, Lesley University, USA \\ ${ }^{2}$ Associate Professor, Director of Creative Arts in Learning Division, Graduate School of Education, Lesley University, \\ USA \\ ${ }^{3}$ Science Teacher, Chungram Middle School, Gangjin-gun, Jeollanam-do, South Korea \\ ${ }^{4}$ Language Art Teacher, Chungram Middle School, Gangjin-gun, Jeollanam-do, South Korea
}

Correspondence: Associate Professor Young Imm Kang Song, Creative Arts in Learning Division, Graduate School of Education, Lesley University, Cambridge, Massachusetts 02138, USA.

$\begin{array}{lc}\text { Received: September 18,2017 } & \text { Accepted: October 31,2017 Available online: November 8, } 2017 \\ \text { doi:10.11114/ijsss.v5i12.2776 } & \text { URL: https://doi.org/10.11114/ijsss.v5i12.2776 }\end{array}$

\begin{abstract}
This international project examined the use of an arts-integrated approach to teaching and learning 8th grade science and language art. It involved two arts faculty collaborating with classroom teachers in the US and South Korea. In the context of the "Tire Art project", students and teachers were guided through several 2D and 3D creative interactions emphasizing innovative uses for recycled car tires and bicycle wheels. In this paper, authors discuss the learning that happened through the arts, and the learning that happened (by teachers) of arts integration methods. It is to be noted that integration is not only about the arts. In fact, if teachers take advantage of this approach, they will discover more connections and bridges between various non-art subjects. When teachers are as affected by innovative approaches as the students, they often feel more confident and empowered in their professional competencies.
\end{abstract}

Keywords: arts integration strategies, environmental arts \& sciences, school collaborations, global project, change in student perceptions, evidence of new kno wledge, environmental education, middle school, contemporary environmental artists; recycled tire art

\section{Introduction}

Since ancient times, cultures across the world have transferred knowledge to younger generations by integrating the arts into their teaching. Martha McKenna and Gene Diaz (2017) explain:

In ancient Greece, Plato reflected on drama as moral education and Pythagoras integrated science into music. In the Middle Ages, teachers used narratives in stained-glass windows and mosaic designs to reflect the stories of various religions and cultures. The pictographs of Chinese written language have always told their own stories, just as the colorful designs of Guatemalan huiples are representative of the wearers' home villages. Hopi kachina dolls teach moral lessons, and the griots of western Africa have long been the storytellers for whole cultures. (p. 181)

Authors know that arts integration has long been an essential part of education, so in this paper authors investigate the effectiveness and usefulness of such arts integration. Currently, there are increasing numbers of theories about the power of arts integration, which authors will explore in more detail in the literature review. But in this article, authors offer an example of the theory applied to practice in real educational settings - one in a South Korean middle school, and one in the United States. Authors chose to focus on the topic of environmental education because the planetary environment is becoming a more and more urgent topic, and because working to protect the environment involves multidimensional and multidisciplinary processes (Song, 2009). Therefore, it is important to understand what a young student, an educator, parents, a community member, or a government official can do.

As artists and educators, it is our responsibility to promote environmental awareness and encourage interest in local environmental issues among students, and authors have come to see arts integration as a powerful vehicle. In this case, authors look at designing class projects with everyday objects which have been used and thrown away - and arrive at 
discarded car tires and bicycle wheels.

\section{Research Purpose and Questions}

The purpose of this research is to examine how arts-integrated teaching and assessment may facilitate better environmental education for students and encourage higher-level thinking and creativity across subjects. Another goal of this project is to estimate the improvements that are obtained regarding students' research abilities, group collaboration skills, data analysis and classification skills, and presentation skills, when the subjects are taught through some integrated curricula connecting science, visual art, and language arts classes. Furthermore, the project investigates whether this type of integrated pedagogy would be effective in raising environmental awareness for middle-school students, and whether they would be willing to participate in understanding and solving environmental problems of the society.

The project has been a collaboration between two countries. Two groups of schoolteachers and students in the eighth grade in the US and South Korea participated in the project on the same topic in different ways depending on the conditions in each school. During the project, professors who co-designed the project participated directly and collaboratively with classroom teachers by co-teaching and observing the students' progress. The collected student drawings, written responses and poetry have been used to draw some final conclusions about the effectiveness of integrated education, and will be used to improve curricula for middle-school education in this age of globalization.

\section{Literature Review}

\subsection{Environmental Education through the Arts}

Barbara C. Matilsky (1992) explains that "Since the late 1960s, an important new art movement has emerged to reestablish a vital link to nature by communicating an experience of its life-generating powers" (p. 4). Artists during this time developed a new awareness and conceptualization of human connections to the environment, and began to express this broader interpretation in a collection of artworks. This shift is now referred to as the environmental arts movement. Environmental art can be defined as "artwork created by artists concerned with the state of our environment worldwide, and with their local situation" (Hull, 2016, p.3). It is art that "helps improve our relationship with the natural world" (Greenmuseum, 2016, p. 1). Some artists interpret nature by creating artwork that delivers information about nature, natural phenomena, environmental processes, and critical environmental problems. Other artists utilize and interact with elements of nature - wind, water, thunder, and lightening - in creating their works. In another strategy, artists use ecological art as a medium for their proposals about how to best coexist with nature. Still other artists reclaim, restore, and remediate the damaged environment in an artistic and aesthetic way (Greenmuseum, 2016).

Even though there exist so many environmental artworks, the art world and the educational spheres are not well integrated. There seems to be a gap in utilizing arts resources that could be useful in educational settings. If there were greater integration of the two domains via viewings and discussions with artworks in educational settings, there could be significant benefits to students.

According to Young I. Song (2008), in considering environmental education today in grades K-8, she has observed “three major problems with much of today's environmental education: first, an attitude of emotional detachment from nature; second, an emphasis on a reactive rather than preventive approaches; and third, the limited scope and perspective of environmental education in general. Each of these severely detracts from the potential positive impact of environmental education and merits remediation" (p. 13). As a possible solution to these three major problems, educators can learn to integrate environmental arts into their curricula, discovering the uses of natural or recycled materials in new and thought-provoking ways. Such new methods can help students both understand and appreciate the natural world. Such integrated teaching can help education be more applicable, inspiring, and enriching for students (Song, 2012). In addition, art brings an experiential dimension to environmental education, which can help build appreciation and awareness, and encourage a sense of shared responsibility for nature that students can carry throughout their lives. Environmental educators and art educators have developed exciting and innovative approaches that unite these fields, and together, they aim to foster powerful cognitive, personal, and moral de velopment (Blandy, Cogdon, \& Krug, 1998; Gablik, 1991, 1995; Lankford, 1997; Neperud, 1997; Song 2008, Stankiewicz, 1997).

\subsection{Arts Integration}

Arts integration is the, "investigation of curricular content through artistic explorations. In this process, the arts provide an avenue for rigorous investigation, representation, expression, and reflection of both curricular content and the art form itself" (Diaz, Donovan, \& Pascale, 2006, p.14). Authors align strongly with the notion that the objectives in art should be as important as the objectives in non-arts content. This project looked equally for links between arts integration and environmental science concepts. Authors would like to avoid making causal claims. As a result, we have designed our study to consider the art and the non-art evidence equally. 
According to Hetland, Winner, Veenema, \& Sheridan (2013), they identified "eight studio habits of mind" (p.6) that are not hierarchical. They are: understanding art worlds; stretch and explore; reflect; observe; express; envision; engage and persist; and de velop craft (p. 6). With this in mind, authors paid close attention to the evidence of learning in both the art and non-art processes. Ni Chang (2012) demonstrated "how drawings are utilized to help a child to acquire a science concept" (p.187). Using drawings before and after an arts integrated approach to science standards and objectives, Chang (2012) observed the evidence of a student's learning and stated that, "There is a clear difference between Kevin's first and second drawings of the spider that demonstrate his increased understanding of the science concept in the dimensions of Characteristics of Organism" (p.189) In this study, students showed increased understanding of the concepts in their second drawings. Chang (2012) noted that, "The use of drawing to support children's acquisition of science concepts made the learning atmosphere more invigorating and enjoyable" (p.191).

Einarsdottir, Dockett, \& Perry (2008) used the strategy of facilitating children's drawings in two separate countries to capture students' impressions of a concept as well as their visual thinking before and after an experience of school. The drawings are evidence of change in student perceptions and ideas. Einarsdottir, Dockett, \& Perry (2008) offered the argument that drawings are valuable evidence of learning because "some children prefer to convey their perspectives and experiences through a combination of verbal and non-verbal means" (p. 8).

\section{Methods}

This project drew upon a variety of collected data, gathered through class observations, interviews, presentations, poem writing, art making, field notes, and document analysis. Pre-and post-questionnaires were collected in the classrooms in both the US and Korea.

The pre-questionnaires were followed by a contemporary art history lesson. Then an art making period was co-facilitated followed by a visual class critique which asked students to identify the elements and principles of design in the work of contemporary artists and in their own collaboratively created artworks.

These first open response questionnaires were distributed before the arts activities to collect evidence of students' baseline knowledge and ideas regarding recycling in their school, family, and larger town and district. This contained questions related to student thinking about recycling processes, recycling vocabulary, ideas about art, and ideas about whether or not they thought it was possible to create art from trash. Adrawing exercise asked the students to draw what "recycling" looks like. Upon completing the multi-level arts activities and the art critique, teachers then facilitated the same questionnaires and drawings. The pre-questionnaire written answers were grouped into larger categories such as: some or no knowledge of recycling, some or no evidence of use of vocabulary, and some or no evidence of new ideas. The pre- and post-drawings were categorized as: presence or absence of abstract symbols, presence or absence of human beings recycling, and the presence of absence of specific references to recycling objects, and an absence or presence of a clear visual relationship to recycling. We will discuss more details in the procedure section.

\section{Project Procedure in Korea}

The project was conducted from April to September of 2016 in South Korea. Chungram Middle School is a public alternative-curriculum school that opened recently in 2013, in Gangjin. The school serves students who seek a more specialized practice-oriented education. For this reason, the curriculum syllabus emphasizes "humanistic education" and "experience-based" field studies rather than typical classroom-oriented curricula.

In Korea, participants included thirty-three students (second graders in a middle school) at the Chungram Middle School in Gangjin, Korea, their science teacher DongSun Min, language art teacher HuiKyeong Kang, and School Affairs Director JaeJun Seo. They worked under the leadership of Associate Professor Young Imm Kang Song, who is in the Creative Arts in Learning Division at Lesley University in Cambridge, MA.

First, a questionnaire survey was conducted before the project began.

\subsection{Phase I: Science Class}

Using the topics of tires and the environment, the class aims to improve students' abilities to carry out research, do collaborative group work, collect and analyze data, and deliver a presentation. Following the survey, Dr. Song and science teacher Mr. Min showed a short video clip to hook the students' interest, and presented a history of the modern-day tire via an interactive question-and-answer session. For example, the teacher asked the following questions and invited the students to guess at the answers.

Q. Who invented the modern-day air-filled tire?

A: The modern-day tire was invented by the veterinarian John Boyd Dunlop (1840-1921). In the 1800s, the wheels of bicycles were covered with cast iron. Dunlop's son, Johnny, had a headache whenever he rode his bicycle, and would occasionally fall over and get hurt. One day, Johnny came with a deflated soccer ball and asked him to fill it with air. 
From the image of his son holding an air-filled soccer ball, he had an idea to create a safer tire. He could cover a bicycle wheel with rubber and insert air to make it taut. Dunlop soon began experimenting and eventually made the first air-filled tire and put it on his son's bike. That was February 28, 1888. Later, Dunlop quit his work as a veterinarian and became a businessman.

Q. Why are tires black?

A: This is because of the color of the chemical additive called carbon black that increases the strength of tires.

Q. What is the origin of the word 'tire'?

A: In 1903, Charles Goodyear, Jr., of the United States was looking for a proper name for a newly developed rubber wheel. It is said that the idea for the name came from his daughter's comment that "the most tired part of an automobile seems to be the wheel".

Q. Why do tires have grooves?

A: For safety. This is to increase friction between the wheel and the ground so that the tire does not slide on the street.

Then, the students were grouped around eight subjects:

1. History of the tire

2. Visiting a local tire factory

3. Tire manufacturing process

4. Waste tire management problems

5. Chemical environmental pollution by burning waste tires

6. Recycling waste tires

7. National and local waste tire recycling centers

8. Collection and recycling status of waste tires

After the groups were formed, Dr. Song and Mr. Min gave simple explanations and brief research directions to the students, and allowed the students to select their own presentation methods. Through the two-week research period, the students looked at works of environmental groups such as The Earth Tire Foundation through online research. Students also surveyed local tire recycling centers to collect data: They asked questions such as:

- How many recycling centers are there in the town?

- What do the recycling centers do?

- What kind of ways can the tires be recycled?

The students delved further and investigated tire-related environmental issues such as the disposal of tires in landfills, toxins in the tire debris, and the pollution from the disposal of waste tires. When students seemed stalled in their projects, Mr. Min tried to assist indirectly in a variety of ways. For one student stuck during the research process, he suggested some potentially useful search keywords. For another student who complained that the factory workers he interviewed provided unsatisfactory answers, Mr. Min provided the factory manager the question list in advance, so that the manager could prepare and provide more comprehensive answers to the student.

After two weeks of research, the students presented their information in a diverse assortment of methods. The final presentations included news clips, plays, Prezi, PowerPoint, and stop-motion animations. For some presentations, the students incorporated narrations and quizzes to be more interactive. After the group presentations, the students gave group feedback on their research processes and on the preparation of the presentation. 


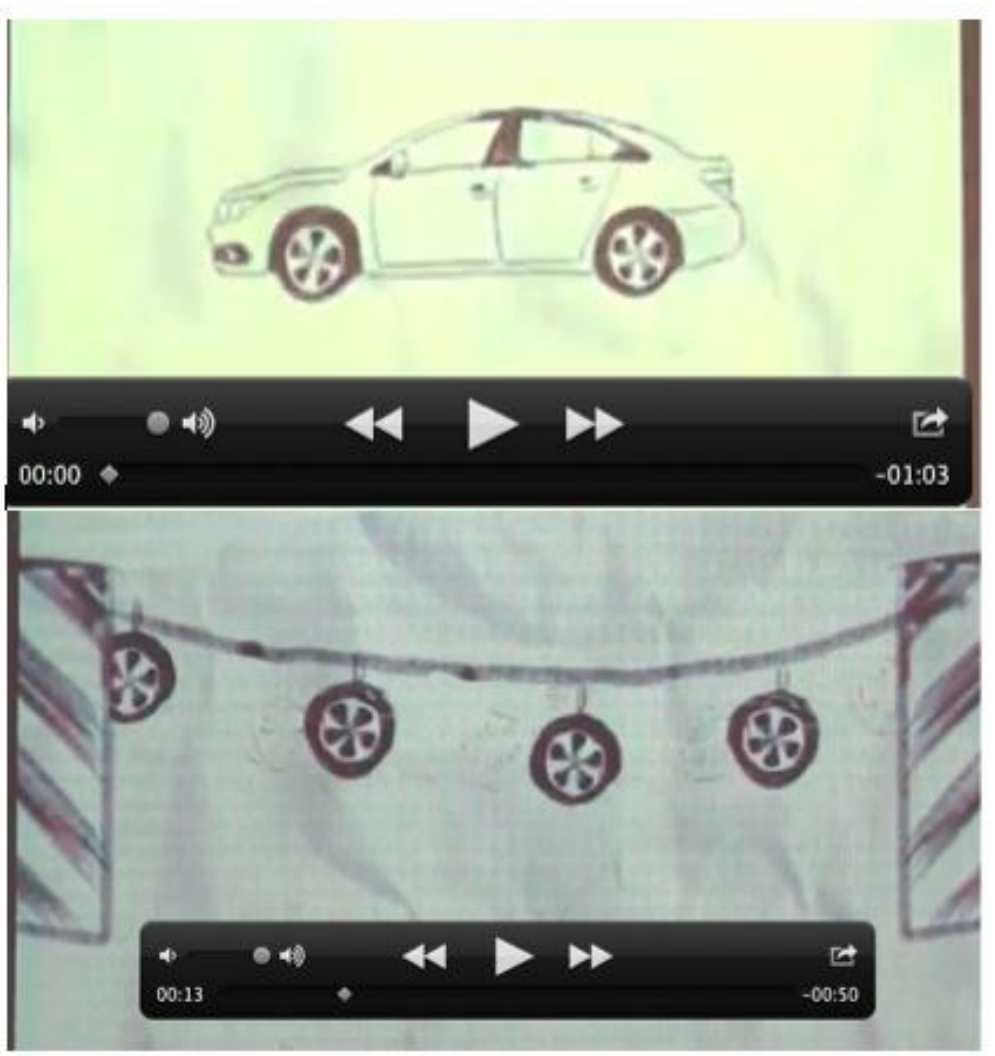

Figure 1. Students' presentation: Animation Creation

The students' acts and presentations for this Phase 1 of the project were very innovative and creative (see figure $1 \& 2$ ). Dr. Song and science teacher Mr. Min learned that instead of presenting a didactic lesson, encouraging students to take initiative on the research process and providing only a few investigative leads might allow a higher level of progress and understanding of the material. Even though this research and presentation process was a first-time experience for many, the students investigated thoroughly and devised exciting methods for group presentations.

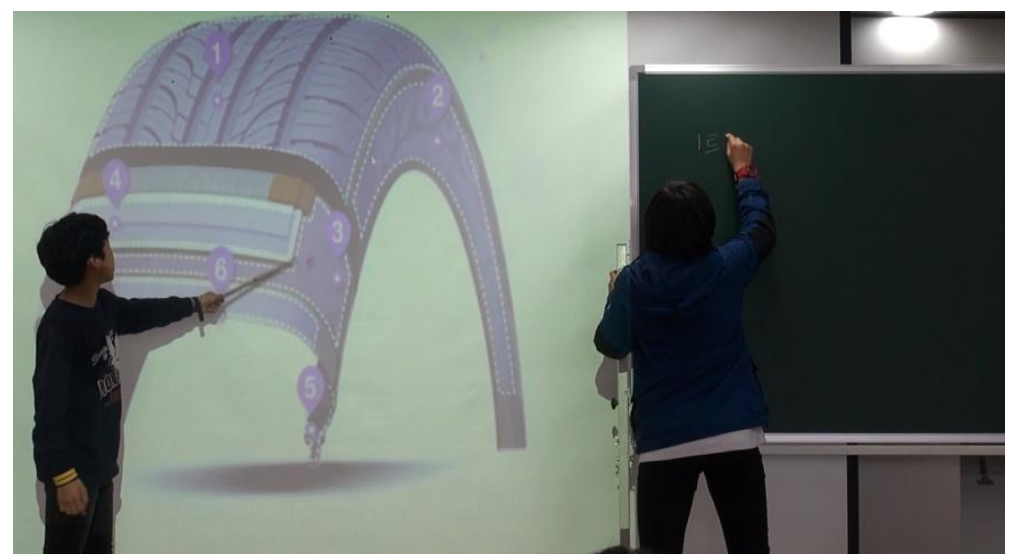

Figure 2. Students' presentation

\subsection{Phase II: Visual Art Class}

Through art class, Dr. Song conducted a workshop on "Environmental Arts". What is the history of environmental art, and how did the environmental arts movement start? Who are some environmental artists, what materials do these artists use, and what processes are there? What meanings are embedded in their works? Through the workshop, students had time to view and engage with various kinds of environmental artworks. In particular, since the project topic was on 
tires, students looked at the tire artworks by Betsabee Romero ${ }^{1}$, Chakaia Booker ${ }^{2}$, $\mathrm{Ji}_{\text {Yong }} \mathrm{Ho}^{3}$, and other artists who made works using recycled tires. Students showed great interest in the field of "environmental art", especially when they looked at Ji Yong Ho's tire art.

In addition, the students showed interest in making artworks themselves using waste tires. This demonstrates what Song (2012) has stated, "Ecological artists have much to offer classroom teachers and community educators. Their vision is bold and many of their works are striking in a way that prompts reactions and discussion" (p.797). It is important that educators provide more opportunities for students to be exposed to environmental artworks.

\subsection{Phase III: Language Art Class}

Vygotsky (1986) and Greene (1995) describe the ways that language and thought are intertwined, and similarly, how language and art can inform each other. Because literature is a means of communicating personal stories and sparking the imagination, Greene suggests that art teachers use literature to generate student ideas (Greene, 1995). Inspired by this suggestion, authors introduced a literature component in the curriculum before starting on art making. In particular, authors wanted to investigate "What would happen if students examined quotes from literature before developing an idea for an artwork? Could reading affect visual thinking and, in turn inspire deeper intention in students' artmaking?" (Berk, 2015, p. 7).

Incorporating these ideas, authors encouraged students to find sentences or a short paragraph from the Korean literature books discussed earlier in the semester in their Language Arts class, and held a session discussing the concepts discussed in their quotes. In addition, the students wrote a "Persona Poem," a type of poem in which the poet becomes an object and speaks from the viewpoint of the object. In our case, the students wrote from the point of view of a tire. At first, when asked to write a persona poem, some students said it was funny to imagine that she or he become a waste tire. However, the students became increasingly immersed as they wrote. As discarded tires, they described emotions such as sadness, pleasure when a waste tire becomes a flower pot, even joy when waste tires are recycled to make a flower field, and gratitude when it is recycled into a new shape. Following the poem writing process, the students transformed their poems into visual forms such as drawings, paintings, and sketches (see figure $3,4,5 \& 6$ ).

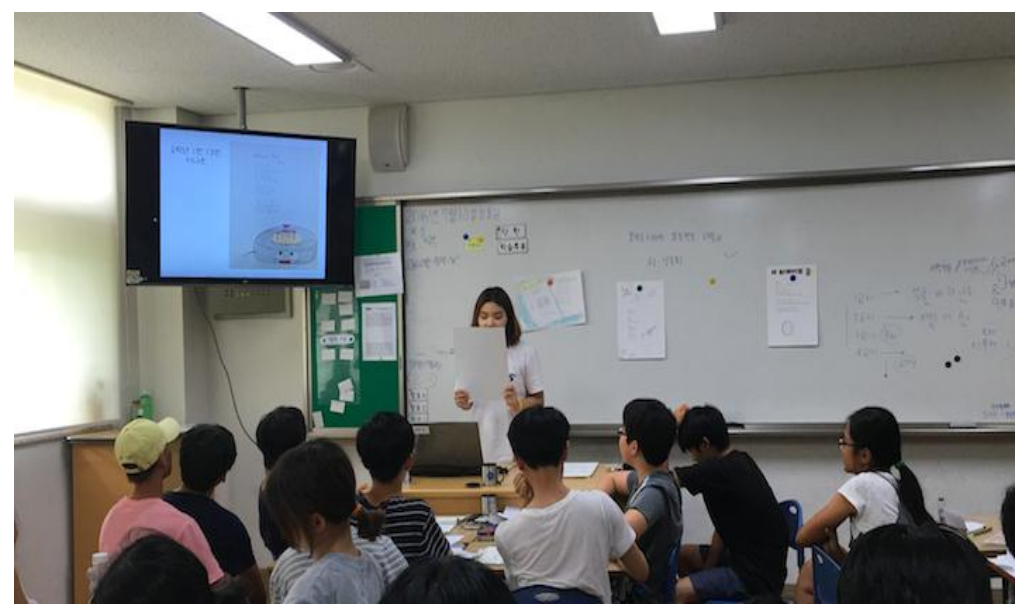

Figure 3. Student's persona poem presentation

\footnotetext{
${ }^{1}$ https://www.betsabeeromero.com

${ }^{2}$ http://www.marlboroughgallery.com/galleries/chelsea/artists/chakaia-booker

${ }^{3}$ http://yonghoji.com/?ckattempt=1
} 


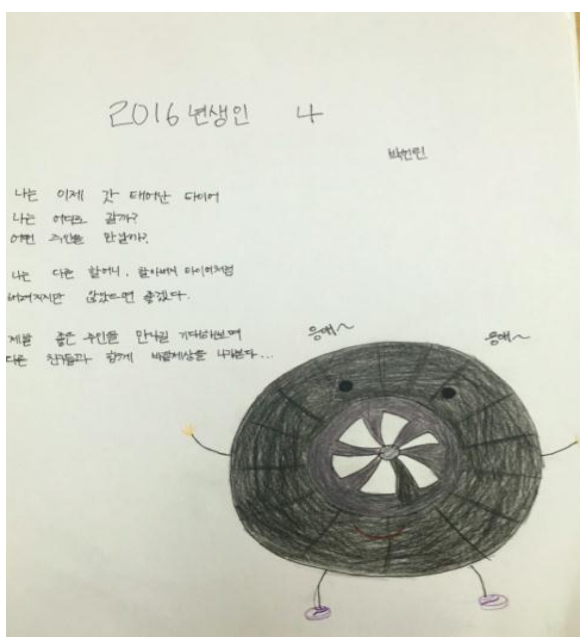

Figure 4. Student's poem \& drawing

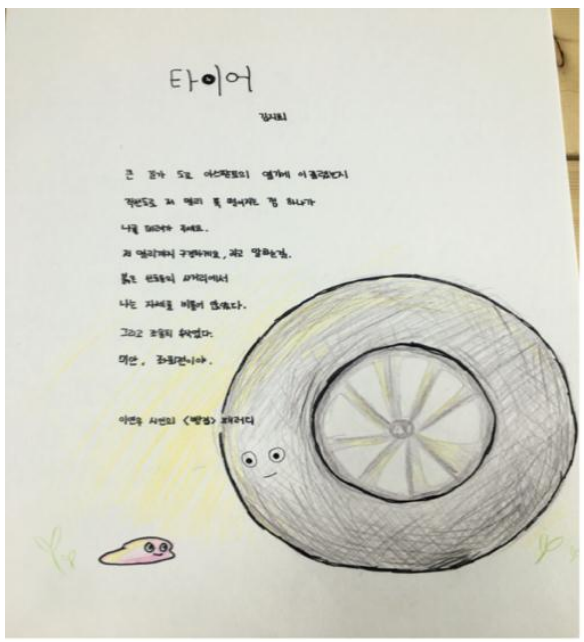

Figure 5. Student's poem \& drawing

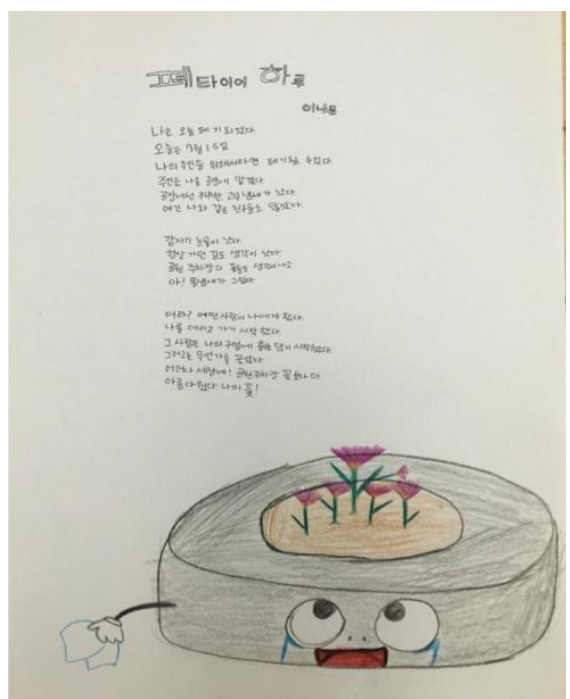

Figure 6. Student's poem \& drawing

Through these activities, students became interested in issues that they previously considered mundane. After writing persona poems, students designed a piece of artwork that they could make using waste tires, and made an exhibition 
combining the poetry and visual art designs. They recited their poetry and presented their feelings about the project, and their classmates gave feedback on the presentations. Mr. Min and Ms. Kang both emphasized that, the students sincerely showed great enthusiasm even though the project started at short notice in the middle of the semester. It was also wonderful that students were more actively and seriously engaged in the project during preparation than in other activities.

Last, a questionnaire survey was conducted after the project was completed.

\section{Project Procedure in the US}

The project was facilitated from April 2016 to June 2016 in the eighth grade of a central Massachusetts public school. A total of six course periods were co-taught. In this school, the participants included 22 eighth grade students at a Massachusetts Middle school. They worked under the leadership of Associate Professor Maureen Creegan-Quinquis , who is the Creative Arts in Learning Division Director at Lesley University in Cambridge, and their teacher, who is a practicing artist and a licensed Teacher of Visual Art in the state of Massachusetts. Classroom teachers are interested in meeting the needs of all students, and teachers' comments lead us to believe that they understand the arts are effective for differentiation and reaching emerging bilingual learners. Many teachers understand that the arts provide a way for presenting multiple modes of entry into content for all students with different learning aptitudes and strengths. Through this project, authors wanted to observe the benefits of providing multiple entry points for students to connect with the concepts being presented. Authors chose these methods to explore more evidence of student thinking and learning beyond just text evidence. Moreover, arts integration strategies had ne ver been used in this focused way in the teaching of the regular art curriculum or the science curriculum in this class. This project was designed to make new learning in the arts visible regarding a non-arts topic such as science and literacy in this class.

\subsection{Phase I: Arts/Science Class}

Using the same research topic and questions about the history of tires and the challenges of disposing of them, Mrs. C's classes carried out research on the computer, did collaborative research work, collected data on recycling processes, and delivered a written presentation. During this research period, Mrs. C also taught the students how to construct a magazine bowl emphasizing the process of turning trash into treasure (see Figure 7). Next, Mrs. C. reviewed Massachusetts Curriculum Frameworks core standards within Standard \#2 Elements \& Principles of Design (www.doe.mass.edu, 2017). This Standard is required content for the Visual Arts license in the state of MA and is included in art teacher evaluations of proficiency. This is considered a foundational language to all art forms including concepts such as: line, shape, color form, pattern, texture, symmetry, balance, emphasis, contrast, pattern, unity, rhythm, and movement. Instruction included exploring these elements in written vocabulary and visual examples. The visuals reinforced older as well as new vocabulary for the students.

Students were invited to respond to a pre-questionnaire. The pre-questionnaire asked fourteen open response questions related to their knowledge of the arts, of recycling, their beliefs and knowledge regarding contemporary art, and their thinking about scientific recycling processes before participation in an arts integrated lesson. Their answers consisted of words and short phrases. The second tool authors used was called a "Pre-drawing". This was an $8.5 \mathrm{x} 11$ " paper with a blue blank circle in the middle. Above it was the prompt, "What does recycling look like? Please draw" (see Figure 8). Students were provided multiple drawing materials from colored pencils to colored markers. The purpose of the drawing was to visually document student thinking and understanding of the concept of the word "recycling" before student participation in an arts integrated lesson. The majority of these first drawings referred only to the universally known symbol of recycling or the symbol on a recycling container. 


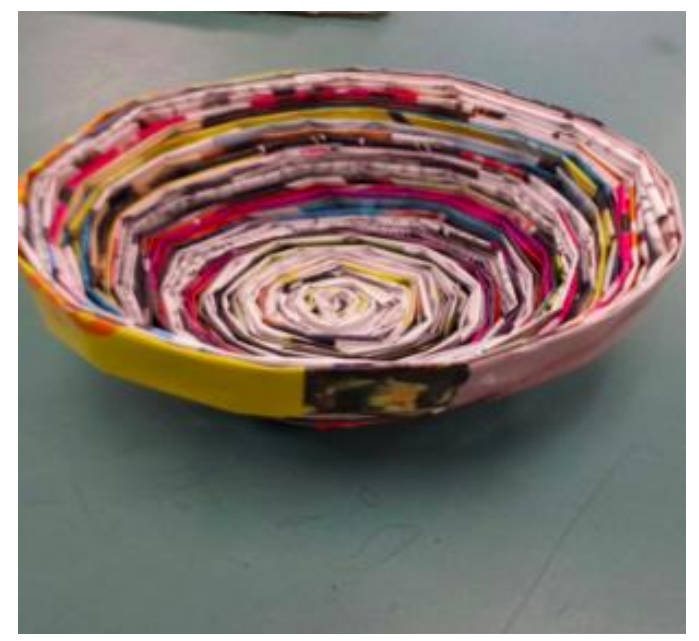

Figure 7. Work by Mrs. C, 2016

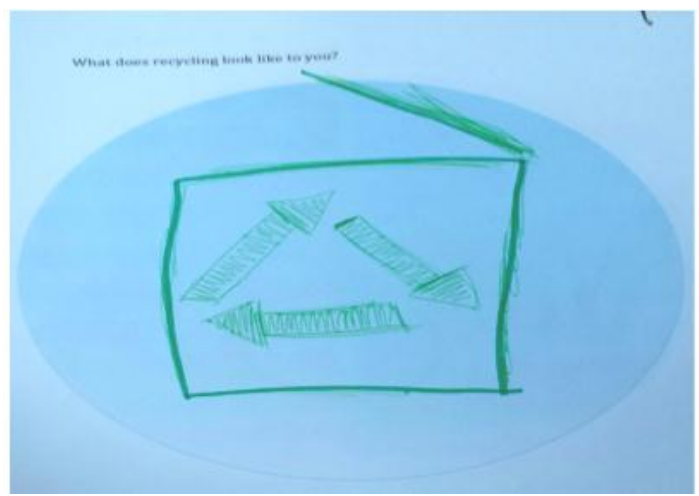

Figure 8. Student Pre-Drawing

\subsection{Phase II: Visual Art Class \& Group Critique}

In Phase two, Associate Professor Maureen Creegan-Quinquis and Mrs. C co-facilitated a contemporary art history lesson titled, "Environmental Arts." In addition to asking students what they notice about the work using Visual Thinking Strategies (Yanewine, 2013). Students were also invited to explain their thinking and to identify what (if any) elements and principles of design they noticed embedded in the works of the artists. Throughout the discussion, students also had time to view and engage with various kinds of environmental artworks through the lens of what they had learned about recycling, upcycling, and repurposing. Students viewed artworks by Betsabee Romero, Chakaia Booker, Ji Yong Ho, and other artists who made works using recycled tires. Students showed great enthusiasm for these artists and had a very lively discussion, especially when they looked at Ji Yong Ho's tire art shark. The students expressed surprise at how the artists must have manipulated the tire material to upcycle and repurpose the tires.

\subsection{Phase III: Collaborative Art Making: Up-cycling and Art-making}

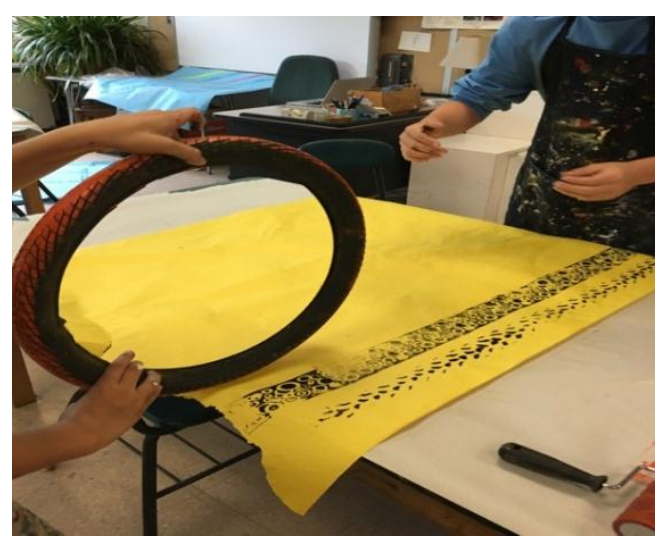

Figure 9. Students Collaborative printing 


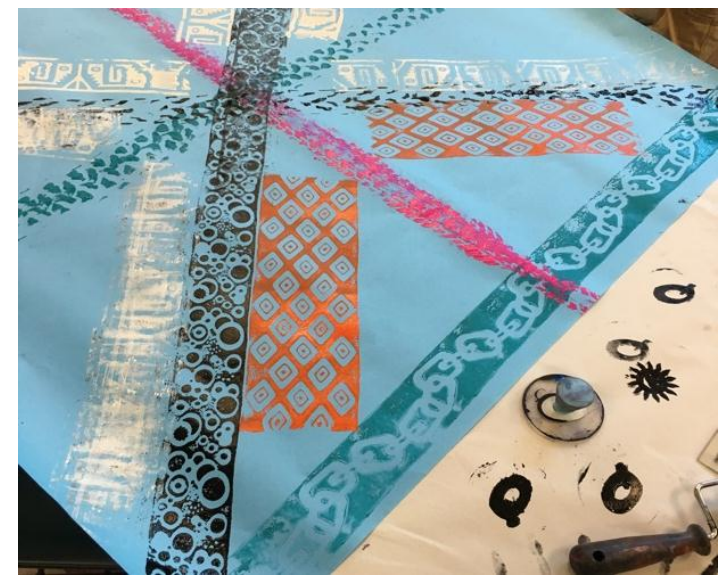

Figure 10. Collaborative student print

Phase three included collaborative printmaking with old bicycle tires with a variety of tread patterns on them. The artworks were created to represent colorful abstract representations of the specific elements of design that the group of students had decided upon together. The steps were: 1. Review of printmaking process and materials. 2 . Review of elements and principles of design This was followed by a teacher demonstration of the kinds of prints that can be made from bicycle treads and a demonstration of how to use the specific printmaking materials. 3. Students watched a demonstration done by the authors on how to collaboratively choose tires, choose colors, and how to physically put ink onto the tires. This was quite a physical process for students which required much collaboration and new work partners. Students did this phase in small groups and successfully visually created and represented an element or concept in an abstract print (see Figure 9). For example, "contrast" (see Figure 10). This led to an opportunity for students to work on very large artworks together. Students participated in group work at different tables. The tables contained different colored water-based printing ink and the ink rollers. When completed, students chose the spokesperson for their group who explained to the class where they show their chosen concept in their design. Students participated in completing more than one large print. Each time, authors observed that they gained more physical control over the medium and the process of printmaking with non-traditional objects. The works were put down flat to dry and to be part of a gallery walk in which students showed their group work and commented upon the work of other groups.

During this phase of creating and sharing, authors observed real cooperation on the part of students. They were enthusiastic and listened to each other's ideas. They were quickly able to make a group decision. They took turns inking the wheels and showed real fascination with the results. While observing, authors heard students at each table make comments like, "I had no idea we could do this in school" and "This is really cool." Authors also heard students communicating their plans out loud and sharing their ideas during the art making process. They were talking with each other regarding what steps should be next and coming to the conclusion together. Authors also observed that students who were not very vocal in earlier classes (or tended to isolate themselves) participating fully and enthusiastically in at least one aspect of this collaborative project.

\subsection{Phase IV: Language Art Class - Poetry Workshop}

Authors understood that students had been exposed to the process of writing a Diamante poem during the school year. In this poem design, typically the first word of the poem undergoes a transformation so that the last word of the poem is the direct opposite of the first. Authors put this poetry activity within the context of recycling trash into treasure. This poetry format provided an opportunity for students to explore a way to express their ideas regarding the possibilities of recycling transforming trash into treasure through participation in the processes of recycling. The students had transformed recycled tires into two-dimensional artworks and next they would transform a recyclable object again through the diamante poem structure.

After a demonstration of how to write a diamante poem, students were asked to write one. Students quickly thought of an object from the recyclable trash and then had to pull upon what they have learned in their previous four phases to complete their poem. As they wrote about the transformative process of their recyclable objects (glass, bottles, styrofoam, etc.), they clearly described recycling procedures and included descriptive words in relation to the physical transformation of objects. Their poems contained evidence of new learning as a result of their researching how an object is recycled, upcycled, and/or repurposed. For example, one student's poem described the process of a crushed glass bottle transformed into a fine piece of jewelry by the end of her poem. Students wrote poems about what recycled rubber, plastic, and glass can become. Another student wrote a poem that contained new thoughts about how it takes a 
community of helpers to transform trash into treasure.

Students volunteered to read their diamante poems out loud. The class was excited by their poetry readings and received applause from their classmates. At this end of this phase, students were given a post-drawing activity as well as the post-questionnaire. The second drawing activity used the same prompt question as the first.

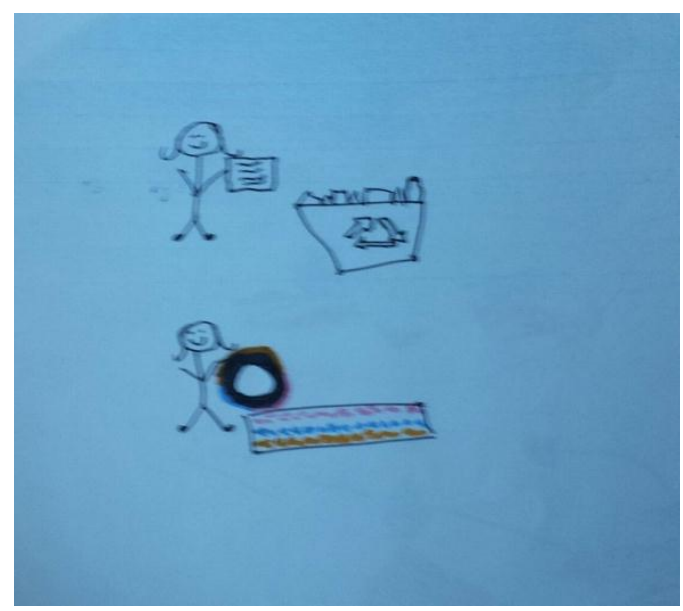

Figure 11. Student Post - Drawing

Many of the drawings following the lesson showed a change in thinking about recycling. Some student examples of post-drawings showing specific activities related to recycling, upcycling and repurposing (see figures 11 \& 12). Most notable are the student drawings in which there are direct depictions of themselves actively recycling. In post drawings, one can see the synthesis of new knowledge and the visual arts tire prints that they created together.

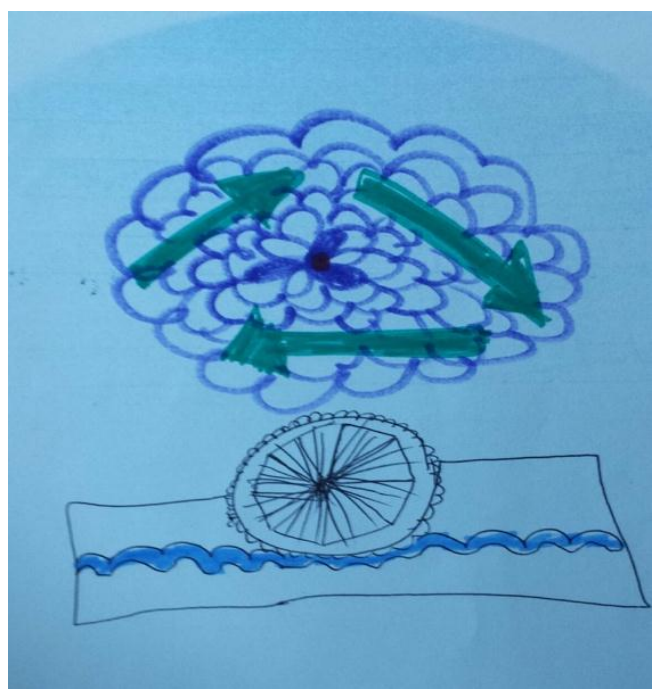

Figure 12. Student Post Drawing

\section{Discussion}

\subsection{Learning through the Arts}

Authors examined whether the arts-integrated teaching approach was able to facilitate better environmental education for students and encourage higher-level thinking and creativity across subjects. In general, Authors found the arts-integrated teaching approach to have had a positive effect. For example, Ms. Kang reports that students expressed much more enthusiasm, less boredom, and more engagement with their peers' presentations when using arts-integrated methods. They also asked several more questions about environmental issues that reflected thoughtfulness, even among students who typically did not speak up in class. They also spoke about local environmental news topics and community issues. Despite initial hesitations given the new approach, this seemed to have been facilitated by the fact that the approach directly elicited "out of the box" thinking, encouraging creativity, weirdness, and imagination in ways that other classes typically did not.

Furthermore, Ms. Kang stated that she wished she had provided her students before with the opportunity to create these 
persona poem and art projects together. Mr. Min also expressed a desire to promote more arts integration pedagogy and to spread these approaches more broadly in Korea, and across various subject matters. This is consistent with the thoughts expressed in Diaz and McKenna (2017), which discusses the importance of using such creative processes that "offer their students options to communicate and express their knowledge and learning in multiple ways (i.e., musical, kinesthetic, poetic, dramatic, visual, and storytelling) (p. 22)." This is especially effective because it allows students with varying abilities to engage, thus "open[ing] up learning to those who have often been left out because of one-dimensional or single-intelligence based teaching practices (Diaz \& McKenna, 2017, p. 22)."

We had the rare privilege of collaborating with a teacher who not only believes in the creative process, but who makes a sincere effort to use the arts to support student learning across the curriculum. Mrs. C's noted, "This research project added to the regular art curriculum in many ways. The most interesting part of this process was co-teaching this unit of study." In addition, she emphasized, "Teachers have different styles and different areas of expertise. By sharing the curriculum, we each had the luxury of spending more time on our area of focus as well as the compounded information provided to the students by two teachers"(2016, personal communication).

\subsection{Learning outside the Box}

Authors also found that the project also helped foster students' research abilities, group collaboration skills, data analysis and classification skills, and presentation skills. As students created their projects and presented the ir works, even those who initially felt challenged in describing the deep meanings behind their artworks were eventually able to convey these ideas more effectively.

When asked to describe what they found surprising, frustrating, or satisfying about their research and presentation process, the students said the following. One Korean student commented, "From the research authors had to do, it was really cool to learn about all the things that go into making a tire." Another complained, "Just the calls I had to make to create the short video clip took two days. I didn't realize connecting with companies would be so difficult." Another noted, "Most of the materials were in English, so it took a lot of time to translate them. It was really cool to learn that there are so many artworks that use tires as their material". Another student said, "Using Prezi as my presentation method, I felt like such a professional!". Yet another said, "I learned that Korea has way fewer recycling-related organizations than the US. I'm thinking of writing a letter to my local government about this."

It is important to keep in mind that educators should help guide their critical thinking and understanding, as students often tend to easily explain the "what", but fail to provide deeper explanations about the "why" (Ramsden, 2003). Especially for better integrating of subjects, educators should consider how they can effectively support both the identifying of critical intentions for their work as well as the successful embedding of them into their final works (Berk, 2015).

\subsection{Learning beyond the Classroom}

To understand how the integrated pedagogy may be effective in raising environmental awareness for middle school students, authors draw on findings from the questionnaire survey in Korea and the U.S before and after the project. In response to the question "What is associated with the word 'environmental'?", there were many words with negative connotations such as 'pollution' or 'waste' before the project started in both countries. In the post-project survey, words with positive or proactive connotations such as 'separate garbage collection', 'recycling', 'conservation', and so on were observed more frequently in both countries. To the question "Do you know in what city/town the community recycling centers are located?", the majority of respondents said that they did not know before the project, but after the project, they became more interested in whether or not there was a local recycling center, and became aware of its location in the town where they live.

To the question "Do you know what the neighborhood recycling programs are?" and "Which day of the week do they collect the recyclable garbage?", the number of students interested and aware of the basics of garbage collection increased slightly in both countries. To a question about whether or not they could make artworks using recycled materials, the number of positive answers increased, and there were many answers commenting that they could make a molding type of artwork. Mr. Min and Ms. Kang believed that this is because Dr. Song gave students a classroom demonstration showing a number of molding artworks made from recycled tires. This helps demonstrate the importance of direct viewing and discussion of environmental artists and their artworks, and that these methods raise awareness among the students about the possibilities that exist.

The specific findings from the questionnaire survey in USA before and after the project were as follows: Authors facilitated a pre-questionnaire before the arts activities and a post questionnaire after the arts activities. Authors found areas of growth and new knowledge in the post-questionnaire. In the pre-questionnaire the majority of students when asked where there is a recycling center in their town replied, "I don't know". The rest of the responses were either 
unfinished or references to "CVS" or "downtown." The Post questionnaire shows an increased number of statements of new understanding the locations and process as a result of their research. In the pre-questionnaire one question asked, what happens to old tires when they are no longer useful? The \#1 answer was "don't know." However, the post-questionnaire which followed the research, arts integration, and art history activities showed an increase in interest and new knowledge of what happens to old tires. The ans wers to post-questionnaires in both countries show changes in beliefs and perceptions regarding what constitutes art. In the post - questionnaire following the arts integration work, authors see an increase in the personal understanding of recycling and more personalized responses regarding seeing the art making potential in recyclables. The post questionnaires showed new understandings of the details of locations as well as an increase in the use of new vocabulary in the science areas of recycling, up-cycling, and re-purposing in both countries. There are also similar qualities in the drawings created by students in both countries in the categories of personification of objects and a more complex relationship to recycling beyond a detached symbol.

\subsection{Teachers Learning New Methods}

Furthermore, as a result of the project, Chungram Middle School educators decided to implement some changes to their teaching and learning methods. Through the years, Chungram Middle School in Korea has wanted to develop its own teaching and learning model suitable for the characterization of an 'alternative middle school' with specialized programs, whose core is based on humanistic education. Teachers tried various teaching methods, such as 'community learning' and 'backward learning' in order to offer learner-centered education instead of instructor-centered education, which is carried more often in most schools. According to several teachers' comments, through this project teachers witnessed a clear possibility of the 'project-based learning' that links the school curriculums and various projects that can be carried out by students. Furthermore, the Chungram Middle School Principal TaeSik Yun, and School Affairs Director JaeJun Seo emphasized that in the future, their school curricula should incorporate more project-based learning; restructure the curriculum-setting procedure in order to integrate multiple subjects prior to the start of the semester; and integrate subjects like history, art, language arts, science, music, language arts, etc.

The project execution was not to be included in the performance evaluation of student activities. Yet, the subject material of 'waste tire' was sufficiently interesting, and it seemed that students wanted to excel in a friendly competition because they learned that the project was being executed simultaneously in an American school. As a result, this project seemed to give students a clear understanding of how and where to undertake research, and to give the school and its teachers an understanding of how project-based learning may integrate multiple topics in multiple subjects. In this regard, authors think this project was a useful example of project-based learning method because it has become a good benchmark for other class projects in in the future.

\section{Conclusion}

Despite the distance between the US and Korean educational systems, the arts integration projects were quite successful. Enthusiasm at the schools was very high and results in both locations were very positive. Howe ver, authors noted that it took outside specialists in arts integration to come to both schools and facilitate these projects because such approaches are not currently part of a typical school day. Authors did observe very sincere interests and enthusiasm on the part of teachers and principals, and their support for the arts is very clear; howe ver, teachers lack the internal support structures for implementing fully arts integrated techniques across all non-art subjects. Authors noted some of the issues which get in the way of teachers doing this work in both countries: the continued separation of subjects which places severe limits on both teachers and on the full exploration of subjects; the practice of allowing fixed amounts of time in which to get things done; the limits of bringing certain materials into schools, thus forcing the outcomes into more abstract words and pictures; the lack of attention paid in schools to life outside of schools such as environmental arts. In addition, at each school the curricular requirements are different in interesting ways. Both countries have arts standards but both have different theoretical approaches to all content areas. Despite these limitations, teachers witnessed how arts integration positively impacted their students, and either reinforce their beliefs that, or came to believe it should be a part of their curriculum.

How might educators learn to use art integration to teach various academic disciplines? Authors recommend that institutions consider offering some professional development that includes arts integration strategies to achieve core objectives. These can be simple, aligned with current curricula, and not very expensive. Authors have found that teachers who have studied how to integrate the arts experience their own lives changed, and have a renewed enthusiasm for teaching. They are often much more successful at reaching more students effectively. It may be easier to implement this kind of professional development if the school has culture of open mindedness and enthusiasm for innovative teaching approaches. Increasingly in the US there is willingness on the part of subject matter teachers to discuss innovative and creative ways to approach teaching. Certainly, in the Korean school there was eagerness to try new methods. 
Finally, it is to be noted that integration is not only about the arts. In fact, if teachers take advantage of this approach they will discover more connections and bridges between various non-art subjects. When teachers are as affected by innovative approaches as students, they often feel more confident and empowered in their professional competency. Administrators are encouraged to open ways for education to occur, education in the broadest sense of the word, education that has implications for life beyond school walls. They have the power to invite approaches and subject matter into schools, in the hope that the education delivered can affect life outside and beyond schools. In the case of environmental education, the implications are particularly obvious as planetary degradation continues.

\section{Acknowledgements}

The authors thank the participants of the project in both countries. The authors also express their gratitude to TaeSik Yoon (Principal) and JaeJoon Seo (School Affairs Director) at Chungram Middle school for their support.

\section{References}

Berk, S. (2015). Using literature to activate critical intension in secondary student art. Art Education, Sep. 2015, 6-12.

Blandy, D., Cogdon, G., \& Krug, D. H. (1998). Art, ecological restoration, and art education. Studies in Art Education, 39(3), 230-243. https://doi.org/10.2307/1320366

Chang, N. (2012). The role of drawing in young children's construction of science concepts. Early Childhood Education Journal, 40, 187-193. https://doi.org/10.1007/s10643-012-0511-3

Diaz, G., \& McKenna, M. (Eds.). (2017). Preparing educators for arts integration: Placing creativity at the center of learning. New York: Columbia University, Teachers College Press.

Diaz, G., Dono van, L., \& Pascale, L. (2006). Integrating the arts across the content areas. Huntington Beach: CA. Shell Education publishing.

Einarsdottir, J., Dockett, S., \& Perry, B. (2008). Making meaning: Children's perspectives expressed through drawings. Early Childhood Development and Care, 179(2).

Gablik, S. (1995). Connective aesthetics: Art after individualism. In S. Lacy (Ed.), Mapping the terrain: New genre public $\operatorname{art}$ (pp. 74-87). Seattle: Bay Press.

Gablik, S. (1991). The Reenchantment of Art, London: Thames and Hudson.

Greene, M. (1995). Releasing the imagination: Essays on education, the arts, and social change. San Francisco, CA: Jossey-Bass.

Greenmuseum. (2016). What is environmental art? Forum. Retrieved November 5, 2016 from http://greenmuseum.org/what_is_ea.php

Hetland, L., Winner, E., Veenema, S., \& Sheridan, K. M. (2013). Studio thinking 2: The real benefits of visual arts education. NewYork, NY: Teachers College, Columbia University.

Hull, L. (2016). Lynne Hull: Environmental artist: Artist statement. Retrieved November 5, 2016 from http://www.eco-art.org

Krug, D. H., \& Cohen-Evron, N. (2000). Curriculum integration positions and practices in art education. Studies and Art Education, 41(3), 259-277. https://doi.org/10.2307/1320380

Lankford, E. L. (1997). Ecological stewardship in art education. Art Education, 50(6), 47-54. https://doi.org/10.2307/3193688

Matilsky, B. (1992). Fragile ecologies: Contemporary artists'interpretations and solutions. New York: Rizzoli.

Neperud, R. W. (1997). Art, ecology, and art education: Practices \& linkages. Art Education.50(6), 14-21. https://doi.org/10.2307/3193683

Song, Y. I. K. (2008). Exploring connections between environmental education and ecological public art. Childhood Education: Journal of The Association for Childhood Education International, 85(1), 13-19. https://doi.org/10.1080/00094056.2008.10523051

Song, Y. I. K. (2009). Community Participatory Ecological Art and Education. International Journal of Art \& Design Education, 28(1), 4-13. https://doi.org/10.1111/j.1476-8070.2009.01588.x

Song, Y. I. K. (2012). Crossroads of public art, nature and environmental education. Environmental Education Research, 18(3), 2-17. https://doi.org/10.1080/13504622.2012.670208

Stankiewica, M., \& Krug, D. (1997). Art \& ecology. Art Education, 50(6), 4-6. 
Vaughn, K., \& Winner, E. (2000). The Arts and academic achievement: what the evidence shows. The Journal of Aesthetic Education, 34(3/4), 77-89. https://doi.org/10.2307/3333638

Vygotsky, L. S. (1986). Thought and language. Cambridge, MA: MIT Press.

Yanewine, P. (2015). Visual thinking strategies. retrieved on August 1,2017 at https://vtshome.org/

\section{Copyrights}

Copyright for this article is retained by the author(s), with first publication rights granted to the journal.

This is an open-access article distributed under the terms and conditions of the Creative Commons Attribution license which permits unrestricted use, distribution, and reproduction in any medium, provided the original work is properly cited. 